\title{
Opportunistic maintenance policy for a multi-component system subject to random failures
}

\author{
${ }^{1}$ H.ELHADAF ${ }^{2}$ R.BENMANSOUR \\ ${ }^{3}$ H.ALLAOUI ${ }^{4}$ M.TKIOUAT ${ }^{5}$ A.ARTIBA
}

\author{
${ }^{1,4}$ LERMA, Université Mohammed V Agdal, Ecole Mohammedia d'Ingénieurs, Av Ibn Sina, BP. \\ 765, Rabat, Maroc. \\ ${ }^{2,5}$ LAMIH UMR CNRS 8201, Université de Valenciennes et du Hainaut Cambrésis, Le Mont-Houy \\ 59313 Valenciennes cedex 9, France. \\ ${ }^{3}$ LGI2A, Université de l'Artois, 9-rue du Temple-BP 10665-62030 Arras Cedex-France. \\ 1elhadafhouda@hotmail.com
}

\begin{abstract}
In this paper we study an opportunistic maintenance policy (OMP) for a multi-component system. The objective is to minimize the maintenance cost while guaranteeing a minimum level of reliability for the system and for each of its components. We suppose that each component is subject to random failures and at most one spare part of it should be kept in stock or ordering at any time. The lifetime of this system will be divided into several periods. At the beginning of each period we must determine the set of actions (among many others) that will achieve the objective mentioned above. The policy OMP is characterized by two parameters; the first one is the scheduled time for spare ordering and the second one is the period of realization of the maintenance action (if any). These parameters will be derived from the joint optimization of maintenance cost and the inventory cost for each component. Finally, we will give a numerical example to explain the proposed maintenance policy and the optimization procedure.
\end{abstract}

Index Terms- Opportunistic maintenance; preventive maintenance; Multi-component system; Reliability.

\section{INTRODUCTION}

Nowadays, maintenance is the most important issue in each critical activity and the challenges of maintenance are growing especially with the sophisticated industrial systems, which are more complex and multifunctional. Consequently, in the last decades, researchers and practitioners start developing new tools and approches to deal with problems in the areas of maintenance and reliability.

The maintenance activity is dependent on the availability of the necessary resources [19]. Nevertheless, most analytical models assume that these resources are always available. Therefore, most of researches has treated spare parts management and maintenance optimization separately or sequentially $[16 ; 26 ; 17 ; 27 ; 15]$, and even nowadays, little attention has been paid to the joint optimization of the spare parts provisioning and maintenance actions [7]. Such a way, practitioners and researchers are missing the opportunity to achieve substantial savings. Indeed, recent studies have shown that joint optimization of spare parts inventory and maintenance strategies generate substantial gains in availability and cost $[1 ; 5 ; 6 ; 14 ; 25 ; 28]$. In these cases, the demand for spare 
parts arises from both preventive and corrective maintenance.

Recent studies show that the effective use of opportunistic maintenance is beneficial to the overall performance of the production system $[22 ; 29 ; 8 ; 12 ; 9]$. In addition, the grouping of maintenance actions for a set of components is suitable when the cost of access to these components of the same class are expensive. On the other hand, the cost of downtime can also be reduced by effective utilization of opportunistic maintenance.

Generally, after undertaking a maintenance action, the system will not be as good as new; the imperfect preventive maintenance concept is used here to model this reality. Pham and Wang [21] have reported that more than 40 mathematical imperfect maintenance models have been proposed over the last 30 years for estimating the reliability measures and determining the optimum maintenance policies. They have proposed various methods and optimal policies on the imperfect maintenance.

In this paper, we propose an opportunistic maintenance policy (OMP) for a multi-component system subject to random failures. This policy consists in determining at the beginning of each period the maintenance actions to be undertaking on the system. The actions selected are the ones that minimize the maintenance cost while guaranteeing a minimum level of reliability. For each component $C_{i}$, we determine the scheduled time for spare ordering $t_{i}$ and the scheduled time for preventive replacement $T_{i}$ using the joint optimization of maintenance cost and the inventory cost. Without loss of generality, we consider that $T_{1} \leq T_{2} \leq \cdots \leq T_{n}$. If we consider the elements of the system separately, we must intervene on the system at each instant $j T_{i}\left(\mathrm{i} \in \mathrm{N}, j \in \mathrm{IN}^{*}\right)$. Unfortunately, this could be practically inconceivable. For this reason we will not explore all these possibilities but instead we choose a single period $T_{S}$ which will be common to all the elements of the system. The same way, we chose a common time ordering spare parts $t_{s}$.

This paper is organized as follow. Section 2 presents some notations and describes the policy for a single-component system. For this system, we give, the expected cost rate and optimization procedure used to determine the optimal ordering time and the optimal replacement time. Then, based on the results obtained for this single-component system, we develop in section 3 the policy OMP for a multi-component system. To demonstrate the effectiveness of this policy, numerical examples are given in section 4. Finally, section 5 concludes the paper.

\section{THE JOINT OPTIMIZATION OF SPARE PARTS AND PREVENTIVE MAINTENANCE FOR A SINGLE-COMPONENT SYSTEM}

\section{II.1. Model description}

We consider a machine composed of a single component subject to random failures. This extreme case can be considered from that moment the considered component is much more important than others. Furthermore, we suppose that at most one spare part of that component should be kept in stock or in ordering at any time. Armstrong and Atkins [1] analyze the joint optimization of maintenance and inventory to operate this system at the lowest possible long-run average cost rate. The system (i.e. the component) is replaced at failure or at age $T$, whichever occurs first. The ordering for a spare is placed at a scheduled time $d$ or at failure time. Then it's delivered after a deterministic lead time $L(d \leq T-L)$. The component will take over its operation as soon as it is delivered. The objective is to determine jointly the ordering time $(d)$ and the replacement time $(T)$ to minimize the expected cost rate. In order to calculate this cost, we introduce the following notations which we will also be useful in the study of the multi-component system.

\section{II.2. Notations}

$f(x)$ Probability density function 


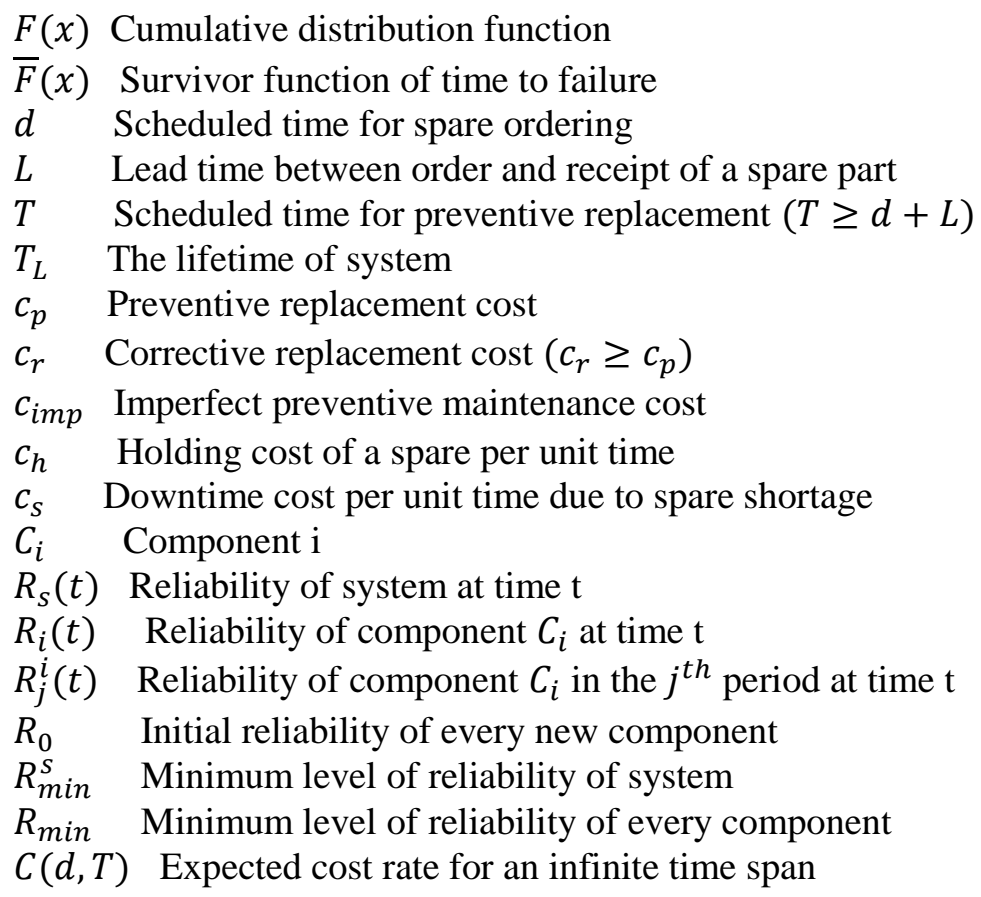

\section{II.3. Cost model}

Since each replacement is a regeneration point, the time between successive replacements can be regarded as one cycle. The expected cost per cycle is the sum of the replacement, holding and shortage costs.

There exist the following four mutually exclusive and exhaustive possibilities in every cycle. For each scenario $m$, we evaluate the total average cost $N_{m}(d, T)$ and the average duration of the corresponding cycle $D_{m}(d, T)$.

Scenario 1: The operating unit fails before the scheduled ordering time $d$.

The order for a spare is placed immediately and the spare is delivered after a lead time $L$. Thus it is necessary to assume the corrective replacement cost and the shortage cost.

$N_{1}(d, T)=\left(c_{r}+c_{s} \cdot L\right) \int_{0}^{d} f(x) \mathrm{d} x \quad---(1)$

$D_{1}(d, T)=\int_{0}^{d}(x+L) f(x) \mathrm{d} x \quad---(2)$

Scenario 2: The operating unit fails between $t$ and the arrival of the ordered spare $d+L$.

The regular order for a spare is placed at time $d$ and the spare is delivered after a lead time $L$. We must assume the corrective replacement cost and the shortage cost.

$N_{2}(d, T)=c_{r} \int_{d}^{d+L} f(x) \mathrm{d} x+c_{s} \int_{d}^{d+L}(d+L-x) f(x) \mathrm{d} x$
$D_{2}(d, T)=(d+L) \int_{d}^{d+L} f(x) \mathrm{d} x$

Scenario 3: The operating unit fails between $d+L$ and the scheduled preventive replacement time $T$.

The spare part is delivered and stored. So, we should assume the corrective replacement cost and the holding cost. 
$N_{3}(d, T)=c_{r} \int_{d+L}^{T} f(x) \mathrm{d} x+c_{h} \int_{d+L}^{T}(x-d-L) f(x) \mathrm{d} x$
$D_{3}(d, T)=\int_{d+L}^{T} x f(x) \mathrm{d} x \quad---(6)$

Scenario 4: The operating unit survive until time $T$.

In this case, we must assume the preventive replacement cost and the holding cost.

$N_{4}(d, T)=c_{p} \int_{T}^{\infty} f(x) \mathrm{d} x+c_{h} \int_{T}^{\infty}(T-d-L) f(x) \mathrm{d} x \quad---(7)$

$D_{4}(d, T)=T \int_{T}^{\infty} f(x) \mathrm{d} x$

Since the cost per cycle is the sum of (1),(3), (5) and (7), then the expected cost per cycle, $\mathrm{N}(\mathrm{d}, \mathrm{T})$, is given by:

$N(d, T)=\left[c_{p}+c_{h}(T-d-L)\right]+\left(c_{r}-c_{p}\right) F(T)-c_{h} \int_{d+L}^{T} F(x) \mathrm{d} x+c_{s} \int_{d}^{d+L} F(x) \mathrm{d} x$

Thus the expected cycle length, $\mathrm{D}(\mathrm{d}, \mathrm{T})$, is computed as follows.

$D(d, T)=T-\int_{0}^{d} F(x) \mathrm{d} x-\int_{d+L}^{T} F(x) \mathrm{d} x$

From the renewal reward theorem [2], the expected cost rate for an infinite time span is the expected cost per cycle divided by the expected cycle length.

Hence the expected cost rate, denoted $\mathrm{C}(\mathrm{d}, \mathrm{T})$, is

$$
\begin{aligned}
C(d, T) & =N(d, T) / D(d, T) \\
& =\frac{\left[c_{p}+c_{h}(T-d-L)\right]+\left(c_{r}-c_{p}\right) F(T)-c_{h} \int_{d+L}^{T} F(x) \mathrm{d} x+c_{s} \int_{d}^{d+L} F(x) \mathrm{d} x}{T-\int_{0}^{d} F(x) \mathrm{d} x-\int_{d+L}^{T} F(x) \mathrm{d} x}
\end{aligned}
$$

In the following subsection we proceed to the resolution of this equation to determine the optimal point $(\mathrm{d}, \mathrm{T})$.

\section{II.4. Optimization Procedure}

Since $C(d, T)$ is unimodal and pseudo-convex in $(d, T)$ as shown by Armstrong and Atkins (1996), the optimal values of $d$ and $T$, can be obtained using a numerical computing software.

We formulate our problem as a constrained nonlinear optimization : Find values of $(d, T)$ that minimize $C(d, T)$ and subject to the constraints $T \geq(d+L)$.

$$
\left\{\begin{array}{l}
\min _{(\mathrm{d}, \mathrm{T})} \mathrm{C}(\mathrm{d}, \mathrm{T}) \\
\left(\mathrm{d}_{0} ; \mathrm{T}_{0}\right)=(0 ; 0) \\
\mathrm{T} \geq \mathrm{d}+\mathrm{L}
\end{array}\right.
$$

We use the function fmincon of Matlab software to search the minimum of $C(d, T)$. This function finds a constrained minimum of a scalar function of several variables starting at an initial estimate. This model is effective for a single-component system, however, in reality, production machines are multi-component systems. Consequently, we study an opportunistic maintenance policy for multicomponent system. 


\section{OPPORTUNISTIC MAINTENANCE POLICY FOR MULTI-COMPONENT SYSTEMS}

\section{III.1. Maintenance actions and Reliability}

Without loss of generality, we consider three possible actions A1, A2 and A3 to designate respectively a preventive replacement, an imperfect maintenance and a "no action" event.

\section{III.1.1. Perfect Preventive Maintenance}

Perfect Preventive Maintenance (A1) is a maintenance action which restores the equipment to the as same as new condition.

In this condition, the reliability of $i^{\text {th }}$ component in the $j^{\text {th }}$ period is defined as :

$R_{j}^{i}(t)=R_{0} R_{i}((t-(j-1) T)) ; \quad(j-1) T \leq t \leq j T$

We notice that at the beginning of the $j^{\text {th }}$ period (i.e $t=(j-1) T$ ) the reliability of the component $C_{i}$ is equal to $R_{0}$.

\section{III.1.2. Imperfect Preventive Maintenance}

Imperfect Preventive Maintenance (A2) is a maintenance action which significantly improves the equipment condition, even without bringing the equipment to a seemingly new condition (better than old) [11].

In this case, the reliability of $i^{t h}$ component in the $j^{\text {th }}$ period is defined as :

$R_{j}^{i}(t)=R_{0, j}^{i} R_{i}\left(\frac{1}{\delta_{i}}(t-(j-1) T)\right) ; \quad(j-1) T \leq t \leq j T---(14)$

Where :

- $\delta_{i}$ is the improvement factor of component $C_{i}$ which is set between 0 and 1 . It can be regarded as the ratio of the life of the surviving parts to their original life.

- $R_{0, j}^{i}$ is the initial reliability of component $C_{i}$ in the $j^{\text {th }}$ period.

According to age reduction model [23], the initial reliability of component $C_{i}$ in the $j^{\text {th }}$ period can be expressed as

$R_{0, j}^{i}=R_{f, j-1}^{i}+\delta_{i}\left(R_{0, j-1}-R_{f, j-1}^{i}\right)$

Where $R_{0, j-1}^{i}, R_{f, j-1}^{i}$ are respectively the initial and final reliabilities of component $C_{i}$ in the $(j-$ $1)^{\text {th }}$ period.

To explain the rationale of equation (15) and illustrate the effects of various actions to reliability, a system whose failure belong to Weibull distribution was used as an example. The system reliability was expressed as

$\mathrm{R}(\mathrm{t})=R_{0} e^{-\left(\frac{t}{\theta}\right)^{\beta}}---(16)$

Where $(\theta, \beta)$ denote the scale and the shape parameters of the Weibull distribution, respectively. For this example, we took $\theta=4000, \beta=2.5, \mathrm{~T}=2000$ and $\delta=0.6$. Under the given parameters, changes in the reliability function of the machine according to different preventive maintenance 
(PM) actions is represented in Figure. 1.

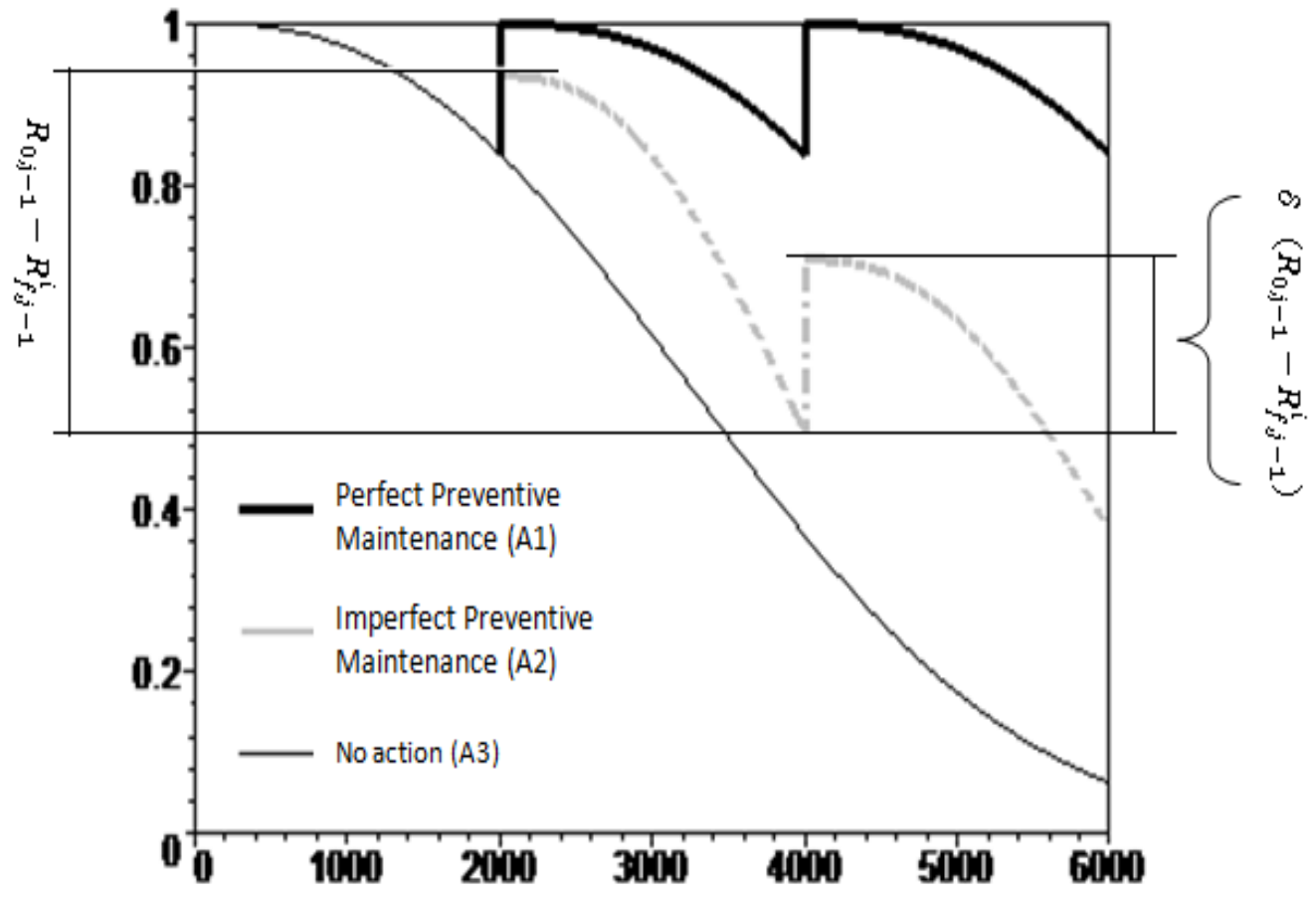

Figure 1 The changing of reliability on different PM actions.

\section{III.1.3. No action event (A3)}

In this case, we decide to do nothing and to postpone any decision to the next period.

\section{III.2. Description of the opportunistic maintenance policy (OMP)}

In practice, for some critical system (bottleneck machine), the manager must ensure the availability of the machine and the reliability of its critical components.. For example, a minimum level of reliability may be required for the system and for each component.

The contribution of this work is the simultaneously satisfaction of both criteria.. Moreover, among the actions that satisfy these criteria, we consider only the action that maximizes the maintenance benefit. In the work of [24], the actions are chosen independently from each other and the model is based on an age replacement policy without taking into consideration the inventory management. In this work, we consider a system composed of several components, the $\left(d_{i}, T_{i}\right)$ (optimal ordering and replacement times) of each component $C_{i}$ can be derived by optimization procedure described in section 2. For a system, if the components are replaced depending on their $T_{i}$ individually, the system availability would be largely reduced and the maintenance cost would be higher due to system shut-down. To avoid this problem, we use the concept of opportunistic maintenance by choosing the system preventive maintenance interval $T_{S}$ as the minimum replacement time among all the $T_{i}, T_{s}=\operatorname{Min}\left\{T_{i}\right\}$ and the scheduled time for spare ordering is $d_{s}=\operatorname{Min}\left\{d_{i}\right\}$. Along the lifetime of the system, we should determine the kind of action to adopt for each component $C_{i}$. We can decide about the actions taken depending on the status of reliability.

For example, if the component's reliability at the next period is less than the set minimum reliability level, i.e. $R_{i}\left(2 T_{s}\right)<R_{\min }$; the component need to be maintained on this period. The latter is 
decided depending on the results of the maintenance-benefit analysis of the system. The maintenance benefit of any component in the $j^{\text {th }}$ period is defined by

$$
B_{i, k}=\frac{\int_{j * T_{S}}^{\infty} R_{j+1}^{i}(t) \mathrm{d} t-\int_{j * T_{S}}^{\infty} R_{j}^{i}(t) \mathrm{d} t}{C_{i, k}}
$$

Where the subscript $i$ denotes the $i^{\text {th }}$ component, $k$ denotes the type of maintenance action and $C_{i, k}$ is the maintenance cost of action $k$.

The action that leads to the maximum maintenance benefit, i.e. $B_{i}^{*}=\operatorname{Max}\left(B_{i, k}\right)$, would be selected for the component.

Therefore the opportunistic maintenance policy can be described as follows:

Step 1: Determine the optimal ordering and replacement times $\left(d_{i}, T_{i}\right)$ of all components by the optimization procedure described in section 2.4.

- Determine the period of the system $T_{S}$ and the scheduled time for spares ordering $d_{s}$.

- Put j $=1$.

Step 2: Put $T_{j}=j * T_{s}$.

a) If $R_{s}\left(2 T_{s}\right) \geq R_{\min }^{s}$ and $R_{i}\left(2 T_{s}\right) \geq R_{\min }$ for all $C_{i}$, then no action is needed.

Move to step 4 .

b) If $R_{S}\left(2 T_{S}\right) \geq R_{\min }^{S}$ and at least there exist one component $C_{q}$ satisfying $R_{q}\left(2 T_{s}\right)<R_{\min }$, then the maintenance action should be taken for this component. The action chosen is the one which maximizes the maintenancebenefit of component $C_{q}$.

c) If $R_{S}\left(2 T_{s}\right)<R_{\text {min }}^{S}$, then maintenance actions should be taken for the components from the set $\{A 1, A 2, A 3\}$. The actions chosen are those that maximize the maintenance-benefit for the system.

Step 3: Calculate the reliability and the maintenance cost of the whole system based on actions adopted in step 2.

Step 4: While $T_{j}<T_{L}$, put $j=j+1$ and go to step 2 .

The procedure ends when $T_{j} \geq T_{L}$

\section{NUMERICAL EXAMPLE}

In order to demonstrate the interest of this maintenance policy, we study below a concrete example with the following assumptions:

1. The lifetime distribution of each component can be determined.

2. Failures can be removed by imperfect preventive maintenance or perfect preventive maintenance.

3. The improvement factor and the maintenance costs of the components can be identified.

For this example a series system which consists of three components is used to explain the policy OMP. The lifetime of each components is supposed to be a Weibull distribution, then the reliability of component $C_{i}$ was expressed as

$$
R_{i}(t)=R_{0} e^{-\left(\frac{t}{\theta_{i}}\right)^{\beta_{i}}}
$$


Where $\left(\theta_{i}, \beta_{i}\right)$ denote the scale and the shape parameters of the Weibull distribution, respectively. The supposed related parameters $\left(\theta_{i}, \beta_{i}\right)$ and the maintenance costs in the example are listed in Table 1. The improvement factor is the same for all components and it is set to $\delta=0.7$. The lifetime of the system is set to $T_{L}=8500 \mathrm{~h}$ and the initial reliability of all components is set to $R_{0}=0.999$.

Table 1 The supposed parameters of the components in the example

\begin{tabular}{|c|c|c|c|c|c|c|c|c|}
\hline Components & $\theta_{i}$ & $\beta_{i}$ & $c_{p}$ & $c_{r}$ & $c_{h}$ & $c_{i m p}$ & $c_{s}$ & $L$ \\
\hline 1 & 2400 & 2.5 & 1000 & 2000 & 40 & 450 & 400 & 20 \\
\hline 2 & 2600 & 3 & 1200 & 2400 & 50 & 540 & 400 & 20 \\
\hline 3 & 3200 & 3.2 & 1400 & 2800 & 60 & 630 & 400 & 20 \\
\hline
\end{tabular}

According to the given parameters, the optimal ordering and replacement times $\left(d_{i}, T_{i}\right)$ of the components can be obtained by the optimization procedure described in section 2 . The numerical calculation gives $d=\{834,1035,1370\}$ and $T=\{854,1055,1390\}$

The period of the system would be $T_{s}=854$ and the ordering time $d_{s}=834$.

We intentionally modify the preventive maintenance cost of the component 2 and 3 by multiplying them by 0.9 , this is the reason why: at the time $T_{s}$, the technicians and tools are already mobilized to work on the machine. So, it would take less time when we intend to improve the reliability of the component 2 or 3 .

Table 2 The maintenance benefits of system

\begin{tabular}{|c|c|c|c|c|c|}
\hline Period & Time (h) & \multicolumn{3}{|c|}{ PM actions } & maintenance benefit of system \\
\hline & & $C_{1}$ & $C_{2}$ & $C_{3}$ & \\
\hline \multirow{6}{*}{$\mathrm{j}=1 / \mathrm{j}=6$} & \multirow{6}{*}{$854 / 5120$} & $A 1$ & $A 1$ & $A 3$ & 0.281 \\
\hline & & $A 1$ & $A 1$ & $A 1$ & 0.246 \\
\hline & & $A 1$ & $A 1$ & $A 2$ & 0.258 \\
\hline & & $A 1$ & $A 2$ & $A 3$ & 0.285 \\
\hline & & $A 1$ & $A 2$ & $A 1$ & 0.197 \\
\hline & & $A 1$ & $A 2$ & $A 2$ & 0.216 \\
\hline \multirow{4}{*}{$\mathrm{j}=2 / \mathrm{j}=7$} & \multirow{4}{*}{$1708 / 5978$} & $A 1$ & $A 1$ & $A 1$ & 0.354 \\
\hline & & $A 1$ & $A 1$ & $A 2$ & 0.360 \\
\hline & & $A 1$ & $A 2$ & $A 1$ & 0.314 \\
\hline & & $A 1$ & $A 2$ & $A 2$ & 0.348 \\
\hline \multirow{4}{*}{$\mathrm{j}=3 / \mathrm{j}=8$} & \multirow{4}{*}{$2562 / 6832$} & $A 1$ & $A 1$ & $A 1$ & 0.266 \\
\hline & & $A 1$ & $A 1$ & $A 2$ & 0.250 \\
\hline & & $A 1$ & $A 2$ & $A 1$ & 0.220 \\
\hline & & $A 1$ & $A 2$ & $A 2$ & 0.275 \\
\hline \multirow{4}{*}{$\mathrm{j}=4 / \mathrm{j}=9$} & \multirow{4}{*}{$3416 / 7686$} & $A 1$ & $A 1$ & $A 1$ & 0.348 \\
\hline & & $A 1$ & $A 1$ & $A 2$ & 0.350 \\
\hline & & $A 1$ & $A 2$ & $A 1$ & 0.306 \\
\hline & & $A 1$ & $A 2$ & $A 2$ & 0.337 \\
\hline \multirow{3}{*}{$\mathrm{j}=5 / \mathrm{j}=10$} & \multirow{3}{*}{$4270 / 8500$} & $A 1$ & $A 1$ & $A 1$ & 0.300 \\
\hline & & $A 1$ & $A 1$ & $A 2$ & 0.290 \\
\hline & & $A 1$ & $A 2$ & $A 1$ & 0.260 \\
\hline
\end{tabular}


INTERNATIONAL JOURNAL OF ENGINEERING TECHNOLOGY AND SCIENCES (IJETS) Vol.7 (1) June 2017 DOI: http://dx.doi.org/10.15282/ijets.7.2017.1.3.1065

\begin{tabular}{|l|l|l|l|l|l|}
\hline & & $A 1$ & $A 2$ & $A 2$ & 0.275 \\
\hline
\end{tabular}

Next, the maintenance benefit of the system is calculated similarly to Equation (15), using the fact that the reliability of the system at time $t$ is the product of the reliability of each component and the maintenance cost is the sum of the maintenance cost of each component.

The maintenance benefit of the system and of each component are as shown in Table 1

The actions that lead to the maximum of the maintenance benefit are reported in Table 3 .

Table 3 The maintenance schedules of the machine using the maintenance benefits of system

\begin{tabular}{|c|c|c|c|c|c|c|}
\hline Period & Time(h) & \multicolumn{3}{|c|}{ PM actions } & System reliability & Maintenance cost \\
\hline & & $C_{1}$ & $C_{2}$ & $C_{3}$ & & 1540 \\
\hline $\mathrm{j}=1$ & 854 & $A 1$ & $A 2$ & $A 3$ & 0.88 & 2710 \\
\hline $\mathrm{j}=2$ & 1708 & $A 1$ & $A 1$ & $A 2$ & 0.72 & 2170 \\
\hline $\mathrm{j}=3$ & 2562 & $A 1$ & $A 2$ & $A 2$ & 0.82 & 2710 \\
\hline $\mathrm{j}=4$ & 3416 & $A 1$ & $A 1$ & $A 2$ & 0.75 & 3340 \\
\hline $\mathrm{j}=5$ & 4270 & $A 1$ & $A 1$ & $A 1$ & 0.82 & 1540 \\
\hline $\mathrm{j}=6$ & 5124 & $A 1$ & $A 2$ & $A 3$ & 0.88 & 2710 \\
\hline $\mathrm{j}=7$ & 5978 & $A 1$ & $A 1$ & $A 2$ & 0.72 & 2770 \\
\hline $\mathrm{j}=8$ & 6832 & $A 1$ & $A 2$ & $A 2$ & 0.82 & 3340 \\
\hline $\mathrm{j}=9$ & 7686 & $A 1$ & $A 1$ & $A 2$ & 0.75 & 0.82 \\
\hline $\mathrm{j}=10$ & 8500 & $A 1$ & $A 1$ & $A 1$ & \multicolumn{7}{l|}{} \\
\hline \multicolumn{7}{|c|}{$R_{\text {min }}^{S}=0.65 ; R_{\min }=0.8 ;$ Total cost $=\$ 24940$} \\
\hline
\end{tabular}

According to these results, the total cost of the preventive maintenance of the policy OMP is $\$ 24940$. We report in Table 4, the maintenance cost of the system and the maintenance actions applied to each component if we use the PM scheduling in [24]. The OMP policy cost is $8 \%$ less expensive than the policy suggested by Tsai and al. [24] and 11\% less expensive than an individual management of each component based on the model suggested in section 2.

Moreover, the reliability changing of the system and the components in the example are shown respectively in Figure. 2 and Figure. 3. We can notice that the reliability of the system is always greater than the minimum reliability of system $R_{\text {min }}^{S}$.

Table 4 The maintenance schedules of the machine using the maintenance benefits of component [24]

\begin{tabular}{|c|c|c|c|c|c|c|}
\hline period & Time(h) & \multicolumn{3}{|c|}{ PM actions } & System reliability & Maintenance cost \\
\hline & & $C_{1}$ & $C_{2}$ & $C_{3}$ & & \\
\hline $\mathrm{j}=1$ & 854 & $A 1$ & $A 1$ & $A 3$ & 0.88 & 2080 \\
\hline $\mathrm{j}=2$ & 1708 & $A 1$ & $A 1$ & $A 1$ & 0.72 & 3340 \\
\hline $\mathrm{j}=3$ & 2562 & $A 1$ & $A 1$ & $A 3$ & 0.88 & 2080 \\
\hline $\mathrm{j}=4$ & 3416 & $A 1$ & $A 1$ & $A 1$ & 0.72 & 3340 \\
\hline $\mathrm{j}=5$ & 4270 & $A 1$ & $A 1$ & $A 3$ & 0.88 & 2080 \\
\hline $\mathrm{j}=6$ & 5124 & $A 1$ & $A 1$ & $A 1$ & 0.72 & 3340 \\
\hline $\mathrm{j}=7$ & 5978 & $A 1$ & $A 1$ & $A 3$ & 0.88 & 2080 \\
\hline $\mathrm{j}=8$ & 6832 & $A 1$ & $A 1$ & $A 1$ & 0.72 & 3340 \\
\hline $\mathrm{j}=9$ & 7686 & $A 1$ & $A 1$ & $A 3$ & 0.88 & 2080 \\
\hline
\end{tabular}


INTERNATIONAL JOURNAL OF ENGINEERING TECHNOLOGY AND SCIENCES (IJETS) Vol.7 (1) June 2017 DOI: http://dx.doi.org/10.15282/ijets.7.2017.1.3.1065

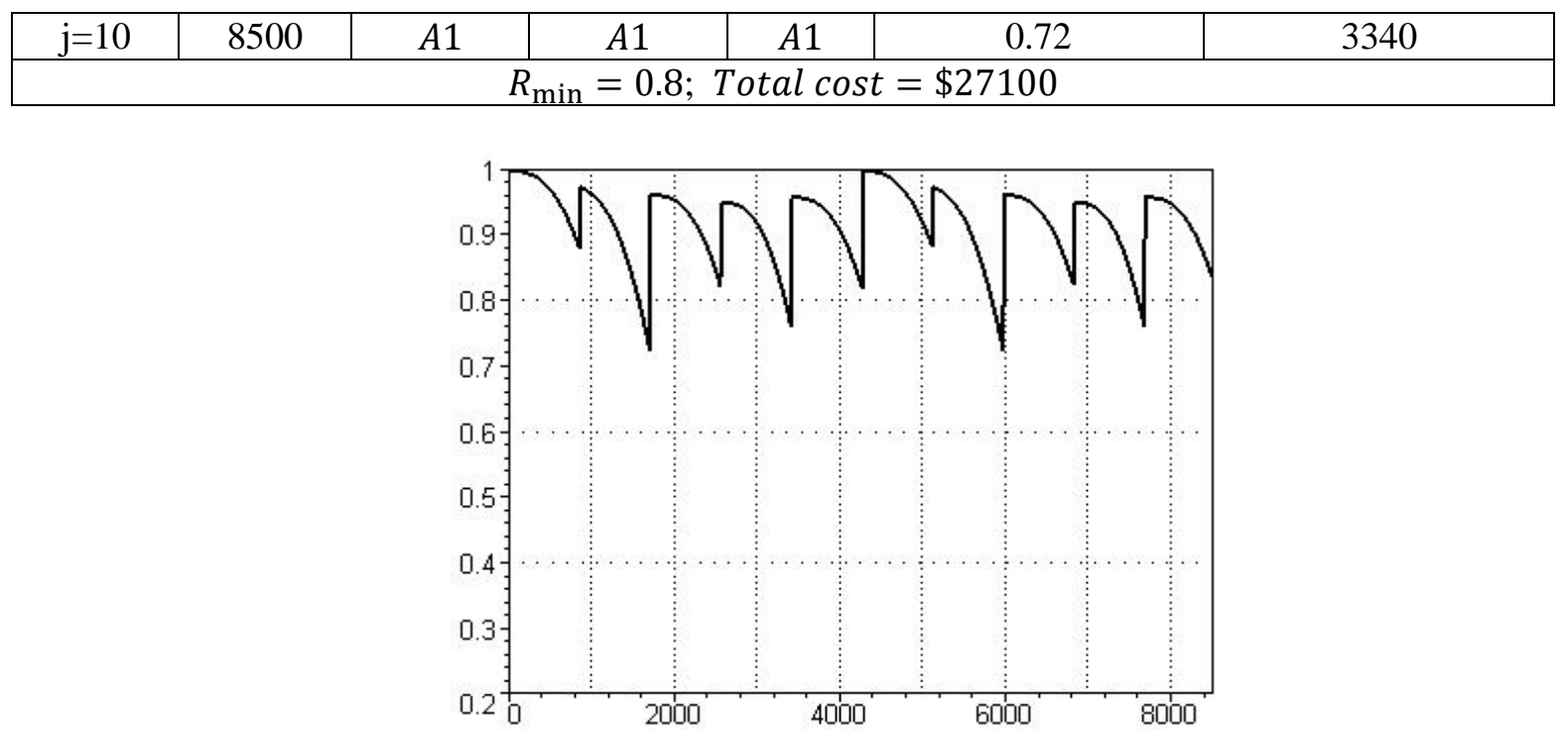

Figure 2 The reliability changing of system under the policy OMP
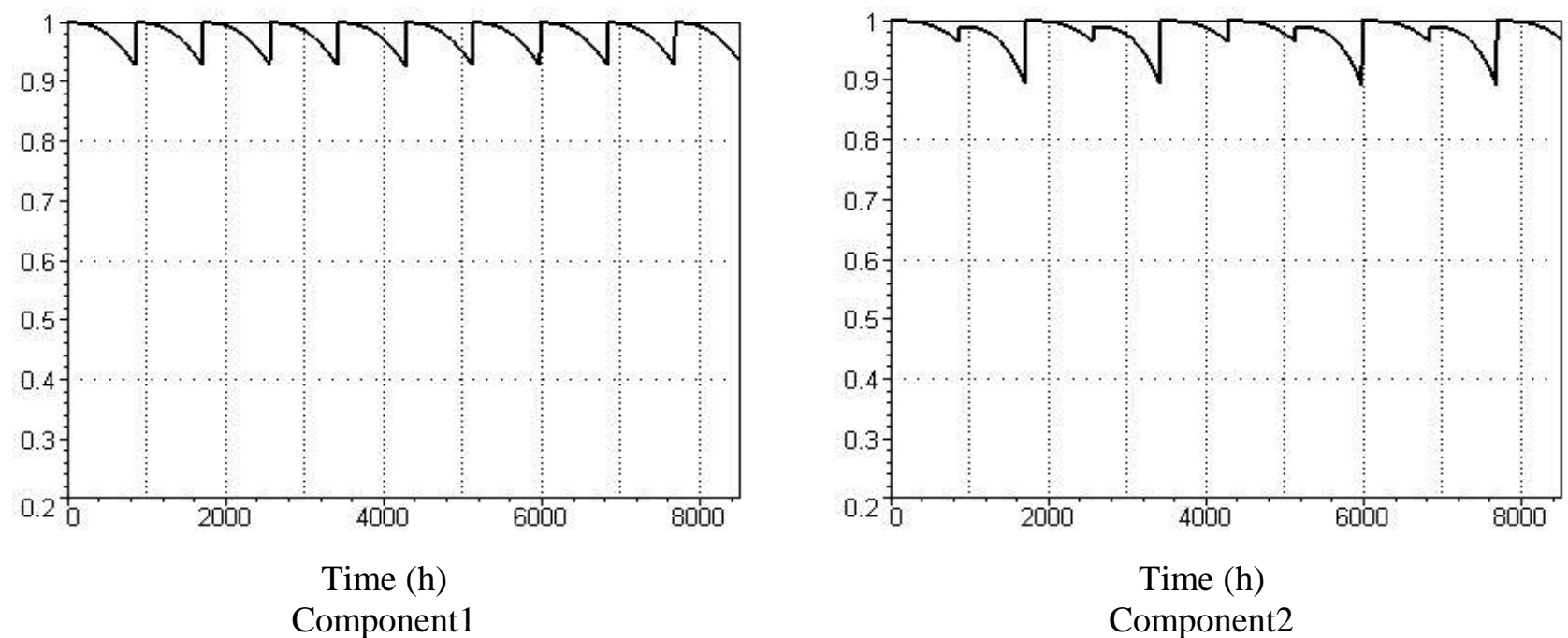

Component1

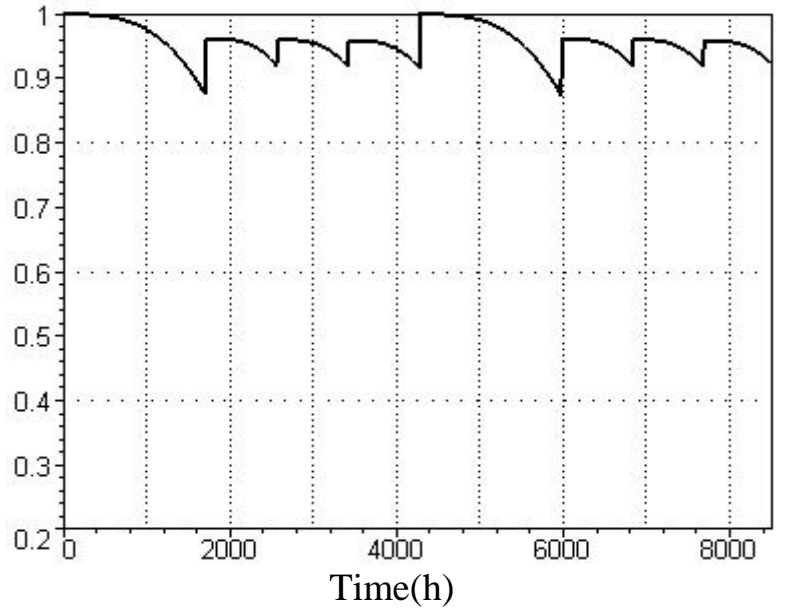


INTERNATIONAL JOURNAL OF ENGINEERING TECHNOLOGY AND SCIENCES (IJETS) Vol.7 (1)

June 2017 DOI: http://dx.doi.org/10.15282/ijets.7.2017.1.3.1065

Component3

Figure 3 The reliability changing of components under the policy OMP

V. CONCLUSION

In this paper, an opportunistic maintenance policy (OMP) is proposed for a multi-component system. This policy is based on the joint optimization of maintenance cost and the inventory for the whole components. In this policy we investigate, at a periodic interval, the opportunity to undergo a specific maintenance actions to all components of the system in order to optimize both the cost and the reliability. Based on a numerical example, we have demonstrated that this policy is more effective than a separate management of each component. Moreover, from a practical point of view, the single scheduled time for spare ordering is easier to implement than a multiple ordering points.

The main idea is to maintain the reliability of the system above $R_{\min }^{S}$ and the reliability of each component above a given level of reliability at a lower cost. In the future research, we would study the gain of the benefit depending on the system architecture (parallel, bridge, parallel-series). A sensitivity analysis would be carried out to investigate the robustness of the model whenever a variation in the minimum level of reliability system occurs.

\section{REFERENCES}

[1] M.J. Armstrong, D.R. Atkins, "Joint optimization of maintenance and inventory policies for a simple system", IIE transactions; 28(5) 415-424. 1996

[2] S. Asmussen, "Applied probability and queues", Springer; Vol.51. 2003

[3] R. Barlow, L. Hunter, "Optimum preventive maintenance policies", Operations Research;8(1)90-100. 1960

[4] M. Ben-Daya, S.O. Duffuaa, A. Raouf, J. Knezevic, D. Ait-Kadi, " Handbook of maintenance management and engineering", Springer Verlag. 2009

[5] A. Brezavscek, A. Hudoklin, "Joint optimization of block-replacement and periodic-review spare-provisioning policy", IEEE Transactions on Reliability; 52(1)112-117. 2003

[6] A. Chelbi, D. Ait-Kadi, (), "Spare provisioning strategy for preventively replaced systems subjected to random failure", International Journal of production economics; 74(1-3)183-189. 2001

[7] K.S. de Smidt-Destombes, M.C. van der Heijden, A. van Harten, " Joint optimisation of spare part inventory, maintenance frequency and repair capacity for k-out-of-N systems", International Journal of Production Economics; 118(1)260-268. 2009

[8] F. Ding , Z. Tian, "Opportunistic maintenance optimization for wind turbine systems considering imperfect maintenance actions", International Journal of Reliability, Quality and Safety Engineering; 18(5)463-481. 2011

[9] F. Ding, Z. Tian, "Opportunistic maintenance for wind farms considering multi-level imperfect maintenance thresholds", Renewable Energy 45; 175-182. 2012

[10] T. Dohi, N. Kaio, S. Osaki, "Optimal ordering policies with time-dependent delay structure", Journal of Quality in Maintenance Engineering; 2(1)50-62. 1996

[11] P. Hoang, "Handbook of reliability engineering", Springer. 2003

[12] W. R. Hou, Z. H. Jiang, "An optimization opportunistic maintenance policy of multi-unit series production system", In Advanced Materials Research 421; 617-624. 2012, February

[13] J. Huang, OG. Okogbaa, “ A heuristic replacement scheduling approach for multi-unit systems with economic dependency", International Journal of Reliability Quality and Safety Engineering 3; 1-10. 1996

[14] M.A. Ilgin, S. Tunali, "Joint optimization of spare parts inventory and maintenance policies 
using genetic algorithms", The International Journal of Advanced Manufacturing Technology; 34(5) 594-604. 2007

[15] J. Jaturonnatee, DNP. Murthy, R. Boondiskulchok, "Optimal preventive maintenance of leased equipment with corrective minimal repairs", European Journal of Operational Research ; 174(1)201-215. 2016

[16] WJ.Kennedy, J. Wayne Pattersonand, L.D. Fredendall, "An overview of recent literature on spare parts inventories", International Journal of production economics; 76(2)201-215. 2002

[17] D. Kumar, "Reliability maintenance and logistic support: a life cycle approach", Springer. 2000

[18] R.. Laggoune, A. Chateauneuf, D. Aissani, "Opportunistic policy for optimal preventive maintenance of a multi-component system in continuous operating units", Computers \& Chemical Engineering; 33( 9)1499-1510. 2009

[19] S. Martorell, M. Villamizar, S. Carlos, A. Sánchez, , "Maintenance modeling and optimization integrating human and material resources", Reliability Engineering \& System Safety, ISSN:09518320, Elsevier. 2010

[20] Y. T. Park, J. SUN, "Optimum ordering policy for preventive age remplacement", J Syst Sci Syst Eng; 18(3)283-291. 2009

[21] H. Pham, and H. Wang, "Imperfect maintenance", European Journal of Operational Research; 94(3)425--438. 1996

[22] E. Thomas, "Contribution à la prise de décision dynamique en maintenance prévisionnelle par formalisation d'un principe d'opportunité", Université Henri Poincaré, Nancy. 2009

[23] Y. T. Tsai, K. S. Wang, H. Y. Teng, "Optimizing preventive maintenance for mechanical components using genetic algorithms", Reliability engineering \& system safety; 74(1) 89-97. 2001

[24] Y.T. Tsai, K.S. Wang, and L.C.A Tsai, "study of availability-centered preventive maintenance for multi-component systems", Reliability Engineering and System Safety; 84(3) 261-270. 2004

[25] A. Van Horenbeek, J. Buré, D. Cattrysse, L. Pintelon, P. Vansteenwegen, "Joint maintenance and inventory optimization systems: A review", International Journal of Production Economics; 143(2)499-508. 2013

[26] J. Vatn, T. Aven, "An approach to maintenance optimization where safety issues are important”, Reliability Engineering \& System Safety; 95(1)58-63. 2010

[27] H. Wang, "A survey of maintenance policies of deteriorating systems", European Journal of Operational Research; 139(3)469-489. 2002

[28] W. Wang, "A joint spare part and maintenance inspection optimisation model using the delaytime concept", Reliability Engineering \& System Safety; 96(11)1535-1541. 2011

[29] X. Zhou, L. Xi, J. Lee, "Opportunistic preventive maintenance scheduling for a multi-unit series system based on dynamic programming", International Journal of Production Economics, Elsevier; 118(2)361-366. 2009 